\title{
Predictors of functional improvement in children and adolescents at a publicly funded specialist outpatient treatment clinic in a Canadian Prairie City
}

Muzi Li ${ }^{\mathrm{a}, \mathrm{b}}$, Carl D’Arcy ${ }^{\mathrm{b}, \mathrm{c} *}$, Xiangfei Meng ${ }^{\mathrm{a}, \mathrm{d}}$

${ }^{\text {a }}$ Department of Psychiatry, Faculty of Medicine, McGill University, Montreal, QC Canada

${ }^{\mathrm{b}}$ School of Public Health, University of Saskatchewan, Saskatoon, SK Canada

${ }^{c}$ Department of Psychiatry, College of Medicine, University of Saskatchewan, Saskatoon, SK Canada

${ }^{\mathrm{d}}$ Douglas Mental Health University Institute, Montreal, QC Canada

* Address for correspondence: Carl D'Arcy, PhD, Applied Research, Department of Psychiatry, Royal University of Hospital, 103 Hospital Drive, Saskatoon, Saskatchewan S7N 0W8, Canada

Email: carl.darcy@usask.ca

Telephone: (306)844-1279 


\begin{abstract}
Children's mental health problems substantially impact their functioning. For clinically treated children and adolescents, we explored the impact of mental health treatment on functioning and identified predictors of functional improvement. Outpatient clinical data from a regional publicly funded specialist outpatient treatment clinic were analyzed. The Child and Adolescent Functional Assessment Scale (CAFAS) was used to assess outcomes. Non-parametric tests were used to compare baseline and exit scores. Logistic regression analysis was used separately for children and adolescents to examine predictors of improvement. Total CAFAS scores at exit showed a significant decrease from initial scores for both age groups, indicating improvements in clients' functioning. Children and adolescents had shared predictors for initial level of dysfunction, length of treatment and the presence of pervasive behavioural impairment (PBI). Primary presenting problem, caregiver support and area of residence were only associated with outcome among children. Clients with higher initial levels of dysfunction and PBI require longer treatment cycles to reach an acceptable outcome. Shortening the length of treatment cycles may improve the efficiency of resource use but can be detrimental to some clients. Personalized treatment should be tailored to the clients with specific characteristics and needs.
\end{abstract}

Key words: CAFAS, functional improvement, child, adolescent 


\section{Introduction}

Children and adolescent's mental health problems substantially impact their functioning in various aspects of life, especially social and cognitive development. Social functioning refers to an individual's interaction with their environment and the ability of fulfill their role within the environment. The environment include work, social and leisure, marital, parental, and extended family (Bosc, 2000; Weissman, 1975). Social functioning is a key aspect of quality of life and an important predictor of wellbeing, happiness, and life satisfaction (Gu et al., 2016). Cognitive functioning is defined as an individual's ability of performing a variety of mental activities most closely associated with learning and problem solving (Neuronup, 2019; Dick and Riddell, 2010). Examples include, but not limited to, verbal, spatial, perception, information processing, learning, attention, memory, decision making, planning, inference and abstraction (Neuronup, 2019; Dick and Riddell, 2010). Children and adolescents with mental health issues tend to have a lower self-worth, negative feelings, poor performance in school, and be involved in unhealthy lifestyle later. Good mental health is as important as good physical health and is essential for the individuals themselves and people surrounding them (Kids Mental Health, 2015).

Outpatient psychiatric treatment, as the most common form of treatment for children and adolescents, has been consistently found to have a positive effect on psychiatric symptoms (Angold et al., 2000; Burns et al., 1999; Waddell et al., 2005). Such treatment typically contains a large number of therapeutic approaches, including individual and group psychotherapy, school-based services, therapeutic foster care, focused family-support programs, and Internet-based cognitive behavioral therapy (Kazdin and Weisz, 1998; Pettersson et al., 2014; PsychGuides.com, 2018). A systematic review identified outpatient treatment as either "well-established" or "probably efficacious" treatment for such mental disorders as disruptive behaviour disorders, anxiety disorders, and autism (Burns et al., 1999). A significant doseresponse relationship was also found between the number of treatment sessions received and improvement in symptoms at follow-up. Eight or more sessions was suggested as being required to produce such positive effects (Angold et al., 2000). 
The Child and Adolescent Functional Assessment Scale (CAFAS) which is a multidimensional level of functioning (LOF) measure has been used to assess functioning of children and adolescents entering and exiting from the mental health care. It consists eight subscales: School, Home, Community, Behaviour Toward Others, Mood/Emotions, Self-Harm, Substance Use, and Thinking. Change in scores on CAFAS subscales are informative as it is important to know whether clients improve generally as well as in specific domains when exiting from treatment (Rohr et al., 2014). Complementary scales allow the assessment of caregiver resources, Family/Social Support and Material Needs subscales are used to examine the extent to which the clients' functioning was disrupted due to limitations in the family's psychosocial resources and caregiving ability. Having an impaired caregiving environment can decrease the probability of successful treatment outcomes (Xue et al., 2004).

Reliability and validity for the CAFAS have been tested by prior studies. Reliability studies have demonstrated satisfactory internal consistency (Hodges and Wong, 1996; Barwick et al., 2004), test-retest reliability (Hodges, 1995; Pernice et al., 1997), and interrater reliability (Hodges and Wong, 1996; Ogles et al., 1999). Numerous studies also provided supportive evidence of construct, criterion, concurrent and predictive validity (Hodges and Wong, 1996, 1997; Hoge, 2002; Quist and Matshazi, 2000; Hodges and Kim, 2000; Hodges and Wotring, 2000; Bastiaansen et al., 2004; Hodges et al., 2000; Hodges et al., 1999; Lambert et al., 2001; Resendez et al., 2000).

Measures such as the CAFAS allow clinicians and health managers to know their clients, the effectiveness of their services in improving client functioning, and the factors that may affect the effectiveness of their services. It is also important to understand special needs for children and youth since they are at different development stages. Parents or caregivers play a large role in children's life during their development of behaviours, social skills, cognition, and emotions that can affect their lifelong health. Similarly, the transition from childhood to adulthood can subject adolescents to a variety of psychological and social pressures. They experience puberty both physical and emotional changes, including hair, breasts, establishing identity, and so on. Rumsey and Harcourt (2007) believed that 
parental influence typically decreases from childhood to adolescent when kids increasingly engage in social network with their peers. Therefore, children and adolescents with mental health problems may require different focuses. For example, children need more support from caregivers, while adolescents may have more issues on substance abuse than children.

Studies have reported on the use of the CAFAS scale for administrative purposes and in clinical settings. It helps linking the level of care and the level of need (Detroit Wayne Mental Health Authority, 2015; Newman et al., 1989; Newman and Hodges, 1995), program evaluation and planning (CAFAS In Ontario, 2017; Detroit Wayne Mental Health Authority, 2015; Herman and Mowbray, 1991; Pokorny, 1991), and predicting subsequent service utilization and associated costs (Detroit Wayne Mental Health Authority, 2015; Hodges and Wong, 1996). Previous studies on the scale also indicated its usefulness in clinical settings, such as case formulation, tracking changes in functioning over time (Boydell et al., 2005; Detroit Wayne Mental Health Authority, 2015), and clinical decision-making about individual consumers (Hodges and Wong, 1996).

However, little research can be found that to what extent, the CAFAS subscales contribute to the overall functioning impairment, neither on the different social-demographic and clinical characteristics associated with changes in clients' functioning (Walrath et al., 2001). Knowledge of the predicators of functional change are important for clinicians, decision-makers, and administrators as they need to know what determinants are associated with functioning improvements and apply personalized care towards clients' needs.

This study aimed to fill the information gap by answering the following questions: (1) did, and how much did, each of the CAFAS subscales contribute to clients' overall functioning impairment? (2) what, if any, changes in total and subscale scores had occurred by the time clients exited treatment? (3) what factors were associated with improvement in client functioning? and, (4) were there any difference between children and youth in the answers to the previous questions? We used clinical data to answer these 
questions. The clinical data were from a publicly funded specialized provider of a range of outpatient mental health treatment services for children and youth in a mid-sized Canadian prairie city.

\section{Methods}

\subsection{Context}

Though federally mandated, provincial governments in Canada take the responsibility of most health services delivered within their provinces with the services provided varying somewhat from province to province. These services include almost all hospital and physician services, prescription drug subsidies, a significant proportion of nursing home, community care services and preventive public health services. Saskatchewan is a prairie province in Canada. These publicly funded health services available at no direct cost to the clients. Saskatoon is a city in central Saskatchewan. It is the largest city in the province with a 2016 census population of 246,376. The Saskatoon Health Region (SHR) was the largest health region in the province, and about $30 \%$ of the province's population resides within the region's geography. SHR was an integrated health delivery agency providing a comprehensive range of services and programs including hospital, long-term care, public health, home care, mental health and addition services, and prenatal and palliative care. In 2015 it served approximately 342,362 residents in urban and rural areas in central Saskatchewan (Saskatoon Health Region, 2015).

Child and Youth Mental Health and Addictions Services (CYMHAS) is the major agency in the Saskatoon region involved in the provision of a continuum of outpatient treatment services to children and youth (and their families) who require mental health treatment. Children and adolescents are generally referred for assessment and treatment from a variety of sources: parents, schools, health professionals, mental health centres, departments of juvenile justice, and social services. The common and over-arching treatments provided include Cognitive Behavioural Therapy, exposure therapies, play therapy, parent education, behavioural therapy, pet therapy, art therapy, and neuro-sequential model of therapeutics. Treatment modalities vary between clinicians and depend on the clients' presenting 
concerns. These clinicians do not prescribe medications. In Saskatchewan, only licensed physicians and registered Nurse Practitioners (to a limited extent) are permitted to write prescriptions for medications.

The Child and Adolescent Functional Assessment Scale (CAFAS) was widely used as a functioning assessment tool within the CYMHAS during the study period. In general, the prototypical treatment cycle (episode) at the time was conceived as using the CAFAS at: an initial assessment, a 3-month assessment, a 9-month assessment, followed by an exit assessment. Some clients can and do terminate treatment earlier than anticipated, whereas others continue treatment over a longer time period. The CAFAS assessments were conducted by social workers, counsellors, and psychologists who were trained by using a well-developed training manual with numerous training vignettes. The assessors may use various sources of information to complete the CAFAS, including interviews with the child and family, interviews with other professionals familiar with the child's behaviors, and record reviews (Bates, 2001).

\subsection{Data resource}

We analyzed data for all those CYMHAS clients aged 6 to 17 years old enrolled in treatment between 2011 and 2014 for their first treatment episode (cycle). Those with incomplete records of initial and exit assessments were excluded. The anonymized data analyzed were from the clinic's individual client clinical (CAFAS) and administrative (Administrative and Management Information System, AMIS) data files. A total number of 1,327 children (645) and youth (682) met inclusion criteria and their data were included in the analysis (Figure 1).

\subsubsection{Child and Adolescent Functional Assessment Scale (CAFAS)}

CAFAS consists of eight subscales (School, Home, Community, Behaviour Toward Others, Mood/Emotions, Self-Harm, Substance Use, and Thinking) and two caregiver resources subscales (Family/Social Support and Material Needs). Each of subscales is scored from 0 to 30, indicating minimal/none to severe impairment. Higher scores indicated greater impairment. Appendix 1 shows the assessment rubric for each subscale and level of impairment. A total score is summed up by the scores 
from the eight subscales. The total score is further divided into five levels of dysfunction: $l$ (scored 0 to 10) - no impairment; 2 (scored 20 to 40) - outpatient treatment; 3 (scored 50 to 90) - additional services beyond outpatient care; 4 (scored 100 to 130) - more intensive treatment than outpatient care and/or multiple sources of supportive care; and, 5 (scored 140 and above) - intensive treatment (inpatient).

\subsubsection{Administrative and Management Information System (AMIS)}

CYMHAS's AMIS - Administrative and Management Information System contains detail sociodemographic (e.g. living arrangement, area of residence and number of residential addresses) and some clinical data (e.g. referral source and parental involvement in capacity development). It was matched with CAFAS data via clients' unique identification number. However, due to a large proportion of missing values in youth age group (approximately 85\%), AMIS predictors were only used in the analysis of predictors of functioning and changes in functioning for the child age group.

\subsection{Measures}

\subsubsection{Outcome}

We defined our outcome as the improvement in level of dysfunction between intake and exit, which was calculated by the formula below, and coded as a dichotomous variable $(1=$ with improvement, $0=$ without improvement):

Improvement in level of dysfunction = level of dysfunction at intake - level of dysfunction at exit

\subsubsection{Predictors}

Socio-demographic variables. Majority of the socio-demographic variables were retrieved from AMIS including information on living arrangement (family of origin, foster homes/other, not provided), area of residence (Northeast, East Centre, South, Southwest, North, West, rural/Prince Albert), number of residential addresses $(1,2,3+)$, referral source (professionals, client family/guardian, justice, school, 
other), and parental involvement in capacity development (yes, no). Information on gender (male, female) was retrieved from the CAFAS dataset.

Clinical variables. Information on primary presenting problem (aggressive behavior, anxiety, relationship difficulties, cognitive difficulties, behavioral concern, traumatic events, depression, other) and number of presenting problems $(1,2,3+)$ was obtained from the AMIS dataset. The CAFAS dataset provided client information on initial and exit CAFAS total scores (0-240) and eight subscales scores (030) which contributed to the total scores, for specific functioning domains. Additional sub-scales which did not contributed to the total scores included: Pervasive Behavioural Impairment (PBI, yes/no), which was defined as moderately or severely impaired on all three of the School, Home, and Behaviour Towards Others domain sub-scales (scored 30 or 20); Caregiver Resources (family/social support, 0-30) which assesses the extent to which the client's functioning was disrupted due to limitations in the family's psychosocial resources, and Caregiver Resources (material needs, 0-30) which examined whether the client's material needs exceed the caregiver's ability to provide. The CAFAS dataset also provided data on length of stay in treatment (0-24+ months) and number of episodes (treatment cycles, 1, 2, 3+).

\subsection{Statistical analysis}

All the analyses were conducted separately for each age group - child (aged 6-11 years) and youth (aged 12-17). Children and youth are experiencing different developmental stages both mentally and physically, thus their mental health treatment needs are different. The cut-point for the age groups studied are based on the definitions of children and youth from the Centres for Disease Control and Prevention (CDC) (CDC, 2015).

Descriptive analyses were used to understand clients' characteristics. Confirmatory factor analyses (CFAs) were applied to test whether and to what extent the eight CAFAS subscales were consistently predicting the overall level of dysfunction. Because the subscale variables were ordinal, CFAs were conducted using robust maximum likelihood estimation with the Satorra and Bentler (S-B) scaled chi- 
squared tests (Satorra and Bentler, 1994). This adjustment for non-normality also allowed us to obtain robust results for standard errors, p-values, confidence intervals, and goodness-of-fit statistics. Model fitting was evaluated by using the following fit statistics: S-B chi-square, comparative fit index (CFI), Tucker Lewis Index (TLI), root mean square error of approximation (RMSEA), Akaike information criterion (AIC), and Bayesian Information Criterion (BIC). By convention, higher CFI and TLI values ( $\geq$ 0.90), and lower chi-square values, RMSEA $(\leq 0.08)$, AIC, and BIC values indicate better fit (Hu and Bentler, 1998, 1999).

Because the subscale and total scores showed non-normality (skewnesses ranged from 0.029 to 4.160 ), non-parametric tests were used to gauge the changes in total and each subscale score and their significances. Higher CAFAS scores indicate more severe impairment. More negative differences were expected when comparing initial and exit scores (exit total score - initial total score). Asymptotic significances were used unless there were less than a total of 25 positive and negative differences, in which cases exact significances were employed.

Multivariable logistic regressions were used to examine determinants associated with functioning improvement. Again, the goodness of fit was tested. Due to the large proportion of missing values in adolescents (approximately 85\%), AMIS variables were not included in the model for youth group and were analyzed separately using chi-square tests. For the purpose of comparison of factors between children and youth, the model for child age group was assessed in two ways: AMIS variables included and not included. We used Stata 14 software (StataCorp, 2015) for all the analyses.

\subsection{Ethical consideration}

This research project analyzed an anonymized data without personal identification and was approved by the Behavioral Research Ethics of the University of Saskatchewan and the Saskatoon Health Region, certificate $14-421$. 


\section{Results}

\subsection{The study sample}

Table 1 presents the socio-demographic and clinical characteristics of the clients. Overall, the majority of the subjects lived in the generally less affluent areas of West (23.5\%) and Southwest (17.6\%) of Saskatoon, lived with family of origin $(86.3 \%)$ with one stable address $(78.6 \%)$, were referred by health professionals (32.2\%), families or guardians (45.9\%), or schools (17.4\%), had only one treatment episode/cycle $(82.1 \%)$, had mostly behavioural concerns $(30.5 \%)$ or anxiety $(25.0 \%)$, received services for 15 months or less $(87.0 \%)$, did not have issues with regard to both caregiver resources - family support (56.9\%) and material needs (92.9\%) - and PBI (90.1\%), and had a Total Score of 90 or less at intake (86.2\%), indicating minimal to moderate level of dysfunction, and their caregivers were not involved in any parental capacity developmental programs $(83.6 \%)$.

\subsection{Contribution of CAFAS subscale scores to overall level of dysfunction at intake}

Figure 2 shows the relationship of subscales and level of dysfunction for children and adolescents. While all eight subscales were positively and significantly predicting children's overall level of dysfunction, it does not show statistically significant relationship for 'Mood' and 'Thinking Problem' domains among adolescents. 'School', 'Home', and 'Behaviour Towards Others' subscales were the top three domains that had the strongest impact to the overall level of dysfunction in both groups. 'Mood', 'Self-Harm', and 'Substance Use' subscales had the least impact on overall dysfunction score among children. 'Substance Use' subscale also had a relatively low association with youth's level of dysfunction compared with other significant subscales. It is noteworthy that 'Self-Harm' subscale negatively predicted the overall level of dysfunction in youth.

\subsection{Difference in CAFAS total score between initial and exit assessment}

Figure 3 graphs the differences in the distribution of Total Score at initial assessment and at exit for child and adolescent client populations separately. Clearly evidence is that substantial improvement 
has occurred for the majority of clients in both age groups. However, it is also evident that there is still a number of clients that remain substantially dysfunctional after a single treatment episode.

CAFAS defines a clinically meaningful and reliable difference in Total Score (dysfunction) as a reduction in Total Score of 20 or more points. A client must have score 20 or more at intake to be included in the analysis, 583 (out of 645) children and 645 adolescents (out of 682) qualified. Of those, $52 \%$ of children and $56 \%$ of adolescents were deemed to have made a clinically significant and meaningful change in functioning. It is obvious that those with higher initial Total Score have a greater potential for achieving a clinically meaningful improvement.

\subsection{Difference in total and subscale scores of CAFAS between initial and exit assessments}

Non-parametric tests (sign tests) were used to compare the differences in total and subscale scores between initial and exit assessment for both children and adolescents (see Table 2). The total score and seven of the eight subscale (except 'Substance Use') scores at exit elicited a statistically significant median decline in functioning impairment compared to initial assessment scores among children. 'School', 'Home', 'Behaviour Towards Others', and 'Mood' subscales showed most improvement. The exact significance test was used for 'Substance Use' due to the small number of negative and positive differences, and the p-value was 0.25 .

For adolescents, the total score and all subscale scores at exit demonstrated a significant median decrease in functioning impairment, compared to initial assessment scores. 'Mood' and 'Self-Harm' subscales declined more (improved) than other subscales.

\subsection{Predictors of improvement in level of dysfunction among children with all AMIS variables} included in the model

There were 76.7\% (495/645) children with completed records for all variables (including AMIS variables) included in the model. Clients who had medium to high initial Total Score, no initial Pervasive Behavioral Impairment (PBI), stayed 12 month or longer for the treatment, had a diagnosis of anxiety, 
relationship difficulties, and depression as primary presenting problems, and who lived in the north and northeast of Saskatoon and rural areas and Prince Albert (a neighbouring city) were more likely to have improvement (decreases) in level of dysfunction (Table 3). These area of residence differences no doubt reflect differences in the socio-economic characteristics of various areas of the City.

\subsection{Comparison of predictors between children and adolescents with AMIS variables analyzed} separately

Due to a large proportion of missing values of AMIS variables in the adolescent group, AMIS variables were excluded from model building process and were analyzed separately by using chi-square tests. For the purpose of comparison, a model was also built for children without AMIS variables. In the regression models, 95.7\% (617/645) of children and 85.8\% (585/682) of adolescents with completed records of CAFAS variables were included in the analysis. Initial Total Score and length of stay were associated with the improvement in level of dysfunction for both groups, while initial PBI showed significant association only in the youth group and caregiver family support only in the children group. Children living in North, Northeast, South, in rural areas and Prince Albert were more likely to improve (decrease) their level of dysfunction at exit, whereas no significant area of residence differences were identified among adolescents.

\subsection{Comparison of predictors in children with and without AMIS variables included in the models}

The predictors of improvement in level of dysfunction were analyzed via two different methods for children - including and not including AMIS variables in the models. Both methods indicated that initial Total Score, length of stay, and area of residence were significantly associated with the improvement in level of dysfunction. Initial PBI and primary presenting problem did not show significant impacts in the model without AMIS variables and separate chi-square tests, respectively. Children with mild impairment on their caregiver family support on initial assessment (10), were more likely to have a decreased level of dysfunction compared to those who had a minimal score (0) in the CAFAS variables only model. 


\section{Discussion}

This study evaluated the structure of the CAFAS as a tool assessing client functioning in various aspects of life, examined the effectiveness of treatment offered by the publicly funded and assessable Saskatoon Mental Health and Addiction Services, and identified the determinants of positive outcomes. All CAFAS subscales values generally contributed to the overall level of dysfunction for both children and adolescents. The Total Score and most of the subscales scores (except the 'Substance Use' in child group which as low to begin with) were at exit significantly decreased compared to initial scores, meaning that client functioning had improved by the time they exited treatment. Common and unique characteristics were associated with functional improvements for both children and adolescents. Among children, those residing in more affluent areas of the City were more likely to have better outcomes. Among adolescents, we lacked data on area of residence. For children and adolescents, there was a positive relationship between length/duration of treatment and improvement with a plateau effect after 21 months.

Our finding is consistent with a CAFAS report in which statistically significant declines in scores were observed for most of the subscales, while the 'Substance Use' subscale did not show significant results for either age groups (Rohr et al., 2014). A similar finding was also observed in children with serious emotional disturbances, indicating that significant functional improvement was found from baseline to 6month assessment (Walrath et al., 2001).

CAFAS scores have been reported as significant predicators of treatment and service utilization (Bates, Furlong and Green, 2006; Hodges and Wong, 1997). Bates et al. (2001) in his review also pointed out the merit of the CAFAS used as a tool for making treatment eligibility decisions and documenting the outcomes.

The Pervasive Behavioural Impairment (PBI) is one of the shared predictors for improvements in functioning among children and adolescents. This finding is in line with the existing literatures. Pervasive behavioural problems were the strongest predictor for poor outcome in 'School' and 'Home' domains, and social interactions (Xue et al., 2004). Emck et al. (2009) also pointed out in their review that children 
with developmental and emotional disorders tended to be restricted in participating active lifestyles and further disruption of their psychosocial and physical development.

Notably, we did not find differences between children and adolescents with regard to their initial Total Score, PBI, and length of stay in treatment as predictors of improvement. All three models generally showed a positive association between improvements (decrease) in level of dysfunction plateauing around 18-21 months (see Table 3). However, staying longer than that in the treatment did not play a role in achieving a better outcome.

Caregiver resources (family support), primary presenting problem, and area of residence were unique factors related to the improvement in functioning in the child age group. Children's mental and psychological development may rely more on parents and caregivers in comparison to adolescents. As a result, family's psychosocial resources (family support) and social economic status (reflected by area of residence) play greater roles in children's mental health and their recovery from dysfunction in comparison to adolescents. This is consistent with the findings of prior studies showing that children's mental health status can be influenced by a number of parental factors, including family's socioeconomic situation (Sheehan, 2017), early parent-child interaction and attachment (Rumsey and Harcourt, 2007). Sheehan (2017) believed that therapeutic interventions for children mostly involved working with the family, thus such factors as socioeconomic status and psychosocial issues can impact the capacity to receive care and the linkages between 'social illnesses and problems' and mental health issues, and then further affect recovery and improvement of health outcomes for children.

\subsection{Strengths and Limitations}

Although this is a prospective case cohort study using standardized assessment of functioning, a few limitations should be noted. First, our analysis was limited to clients' first treatment cycle. We did not report on the predictors or effectiveness of treatment in subsequent treatment cycles. Second, data analyzed here were limited for adolescents due to the large proportion of missing values in AMIS. We are not able to examine the effects of socio-demographic characteristics to the improvement of functioning, 
neither the effects of clinical characteristics with the adjustment for these factors. Third, data were also limited to the variables already collected for standard administrative and clinical purposes. As a result, we did not have enough information to include the analyses of variables such as ethnicity, number of services/visits, medications prescribed by physicians and other treatment received during study period in the analysis. Nor did we have access to the data on how long the treatment effect persisted, whether these clients came back for subsequent treatment of similar problems or new emerging problems. Fourth, the CAFAS was not administered to all clients with behavioural consults or to children under 6 years old not attending school. It was estimated that the CAFAS is administer to approximately $75-80 \%$ of all clients seen by Saskatoon Child and Youth Mental Health and Addictions Services during the study time period. Finally, the analysis concerning predictors of functioning only dealt with clients who had completed their first treatment cycle (episode) using their initial and exit assessment records, which means in-process improvements were not considered (e.g. 3-month and/or 9-month assessment).

In addition, there are queries regarding the credibility of the ratings from clinicians who were working with the child and family due to the motivation of showing improvement, however, Hodges et al. (1998) believed that the treating clinician knows the most about their clients and are the best persons to make judgments about their client's growth. They also suggested some restrictions to reduce bias of the ratings. It is important to note that each rating on the CAFAS must be supported by at least one specific behavioral description of the child. Second, rating errors can be reduced by assessing inter-rater reliability and ensuring that all raters are satisfactorily trained. For this reason, the CAFAS training materials were developed, which can be used for inter-rater reliability tests and ensured that all trainees were receiving standardized training. It might also helpful to reduce intentional rater bias by auditing and the use of independent raters who do not have the same means of obtaining information as do the treating clinician (Hodges et al., 1998).

Our findings provide robust evidence clearly indicating that current outpatient specialist child and adolescent mental health services effectively improved clients' functioning. Treatment does make a 
difference. Clients with a high level of dysfunction at intake and pervasive behavioural problems needed a longer period for treatment to reach a favourable outcome. Shortening the length of each treatment cycle may improve the efficiency of resource use but at the expense of clients that need more time to achieve a more optimal functional improvement level. Personalized treatment services are what is required. Further studies on predictors of functioning improvement are warranted. Future research should also compare CAFAS and other assessment tools to see whether it outperforms than other evaluation tools. 


\section{Acknowledgement}

\section{Study Funding}

ML was funded by a Graduate Teaching Fellowship, University of Saskatchewan, Canada.

\section{Conflicts of Interest}

The authors have declared that they have no competing or potential conflicts of interest.

\section{Contributorships}

ML and CD designed this study. ML conducted the data analysis with the statistical advice from XM. CD assisted with the results interpretation. All the authors prepared the draft of this manuscript. 


\section{References}

Angold, A., Costello, E.J., Burns, B.J., Erkanli, A., Farmer, E.M.Z., 2000. Effectiveness of nonresidential specialty mental health services for children and adolescents in the "real world". J Am Acad Child Adoles Psychiatry, 39(2), 154-160.

Barwick, M., Boydell, K.M., Cunningham, C.E., Ferguson, H.B., 2004. Overview of Ontario's screening and outcome measurement initiative in children's mental health. J Can Acad Child Adoles Psychiatry, 13(4), 105-109.

Bastiaansen, D., Koot, H.M., Ferdinand, R.F., Verhulst, F.C., 2004. Quality of life in children with psychiatric disorders: Self-, parent, and clinician report. J Am Acad Child Adoles Psychiatry, 43, $221-230$.

Bates, M.P., 2001. The Child and Adolescent Functional Assessment Scale (CAFAS): review and current status. Clin Child Fam Psychol Rev, 4(1), 63-84.

Bates, M.P., Furlong, M.J., Green, J.G., 2006. Are CAFAS subscales and item weights valid? A preliminary investigation of the Child and Adolescent Functional Assessment Scale. Adm Policy Ment Health, 33(6), 682-695.

Bosc, M., 2000. Assessment of social functioning in depression. Comprehensive Psychiatry, 41(1), 63-69.

Boydell, K.M., Barwick, M., Ferguson, H.B., Haines, R., 2005. A feasibility study to assess service providers' perspectives regarding the use of the child and adolescent functional assessment scale in Ontario. J Behav Health Serv Res, 32(1), 105-109.

Burns, B.J., Hoagwood, K., Mrazek, P.J., 1999. Effective treatment for mental disorders in children and adolescents. Clin Child Fam Psychol Rev, 2, 199-254.

CAFAS In Ontario, 2017. Welcome to CAFAS in Ontario. Retrievved on September 10, 2018, from http://www.cafasinontario.ca/about.html.

CDC, 2015. Parent information. Retrieved on April 15, 2016, from http://www.cdc.gov/parents/children/index.html. 
Detroit Wayne Mental Health Authority, 2015. CAFAS \& PECFAS guidebook: using PECFAS/CAFAS in practice. Retrieved on September 10, 2018, from http://www.dwmha.com/files/8614/4676/1867/DWMHA.CAFAS.PECFAS.Guidebook_9.8.15.pd f.

Dick, B.D., Riddell, R.P., 2010. Cognitive and school functioning in children and adolescents with chronic pain: a critical review. Pain Res Manag, 15(4), 238-244.

Emck, C., Bosscher, R., Beek, P., Doreleijers, T., 2009. Gross motor performance and self - perceived motor competence in children with emotional, behavioural, and pervasive developmental disorders: a review. Dev Med Child Neurol, 51, 501-517.

Gu, X.M., Ding, C.Y., Wang, N., Xu, C.F., Chen, Z.J., Wang, Q., Yao, Q., Wang, F.L., 2016. Influence of occupational status on the quality of life of Chinese adult patients with epilepsy. Chin Med J (Engl), 129(11), 1285-1290.

Herman, S.E., Mowbray, C.T., 1991. Client typology based on functioning level assessments: Utility for service planning and monitoring. J Behav Health Serv Res, 18, 101-115.

Hodges, K., 1995. Psychometric study of a telephone interview for the CAFAS using an expanded version of the scale. Paper presented at the 8th annual research conference: A System of Care for Children's Mental Health: Expanding the Research Base, Tampa, FL.

Hodges, K., 2000. Child and Adolescent Functional Assessment Scale. Ypsilanti, MI: Eastern Michigan University, Department of Psychology.

Hodges, K., Doucette-Gates, A., Kim, C., 2000. Predicting service utilization with the Child and Adolescent Functional Assessment Scale in a sample of youths with serious emotional disturbance served by Center for Mental Health Services_-funded demonstrations. J Behav Health Serv Res, 27, 47-59. 
Hodges, K., Doucette-Gates, A., Liao, Q., 1999. The relationship between the Child and Adolescent Functional Assessment Scale (CAFAS) and indicators of functioning. J Child Fam Stud, 8, 109122.

Hodges, K., Kim, C., 2000. Psychometric study of the Child and Adolescent Functional Assessment Scale: Prediction of contact with the law and poor school attendance. J Abnorm Child Psychol, $28,287-297$.

Hodges, K., Wong, M.M., 1996. Psychometric characteristics of a multidimensional measure to assess impairment: The Child and Adolescent Functional Assessment Scale. J Child Fam Stud, 5, 445467.

Hodges, K., Wong, M.M., 1997. Use of the Child and Adolescent Functional Assessment Scale to predict service utilization and cost. J Behav Health Serv Res, 24(3), 278-290.

Hodges, K., Wong, M.M., Latessa, M., 1998. Use of the Child and Adolescent Functional Assessment Scale (CAFAS) as an outcome measure in clinical settings. J Behav Health Serv Res, 25(3), 325336.

Hodges, K., Wotring, J., 2000. Client typology based on functioning across domains using the CAFAS: Implications for service planning. J Behav Health Serv Res, 27, 257-270.

Hoge, R.D., 2002. Standardizing instruments for assessing risk and need in youthful offenders. Crim Justice Behav, 29, 380-396.

Hu, L., Bentler, P.M., 1999. Cut-off criteria for fit indexes in covariance structure analysis: conventional criteria versus new alternatives. Struct Equ Modeling, 6:1, 1-55. DOI: 10.1080/10705519909540118.

Hu, L., Bentler, P.M., 1998. Fit indices in covariance structural modelling: sensitivity to underparameterized model misspecification. Psychol Methods, 3, 424e53.

Kazdin, A.E., Weisz, J.R., 1998. Identifying and developing empirically supported child and adolescent treatments. J Consult Clin Psychol, 66, 19-36. 
Kids Mental Health, 2015. Children's mental health is without a doubt the most important aspect of any child's social and cognitive development. Retrieved on July 14, 2017, from

\section{http://www.kidsmentalhealth.org/.}

Lambert, E.W., Wahler, R.G., Andrade, A.R., Bickman, L., 2001. Looking for the disorder in conduct disorder. J Abnorm Psychol, 110, 110-123.

Loeber, R., 1982. The stability of antisocial and delinquent child behaviour: A review. Child Dev, 53, $1431-1446$.

Newman, F.L., Griffin, B.P., Black, R.W., Page, S.E., 1989. Linking level of care to level of need: Assessing the need for mental health care for nursing home residents. Am Psychol, 44, 13151324.

Newman, F.L., Hodges, K., 1995. Developing outcome assessment measures for children, adolescents, and adults to support a provider profile in Indiana. Paper presented at the meeting of the Second Annual Florida Conference on Behavioral Healthcare Evaluation, Orlando, FL.

Neuronup, 2019. Cognitive functions. Retrieved on January 14, 2019, from https://www.neuronup.com/en/areas/functions.

Ogles, B.M., Davis, D., Lunnen, K.M., 1999. Inter-rater reliability of four measures of youth functioning. In J. Willis, C. Liberton, K. Kutash, \& R. Friedman (Eds.), The 11th annual research conference proceedings, a system of care for children's mental health: Expanding the research base (March 8 to March 11, 1998; pp. 321-326). Tampa, FL: University of South Florida, Louis de la Parte Florida Mental Health Institute, Research and Training Center for Children's Mental Health.

Pernice, F., Gust, J., Hodges, K., 1997. A structured interview for collecting objective clinical data. In C. J. Liberton, K. Kutash, \& R. M. Friedman (Eds.), 10th annual research conference proceedings: A system of care for children's mental health: Expanding the research base (pp. 471-476). Tampa, FL: Research \& Training Center for Children's Mental Health. 
Pettersson, R., Soderstrom, S., Edlund-Soderstrom, K., Nilsson, K.W., 2014. Internet-based cognitive behavioral therapy for adults with ADHD in outpatient psychiatric care: a randomized trial. $\mathbf{J}$ Atten Disord, 21(6), 508-521.

Pokorny, L.J., 1991. A summary measure of client level of functioning: Progress and challenges for use within mental health agencies. J Behav Health Serv Res, 18, 80-87.

PsychGuides.com., 2018. Types of Mental Health Treatments: outpatient mental health treatment. Retrieved on September 10, 2018, from https://www.psychguides.com/guides/types-of-mentalhealth-treatments/.

Quist, R.M., Matshazi, D.G.M., 2000. The Child and Adolescent Functional Assessment Scale (CAFAS): A dynamic predictor of juvenile recidivism. Adolescence, 35, 181-192.

Resendez, M.G., Quist, R.M., Matshazi, D.G.M., 2000. A longitudinal analysis of family empowerment and client outcomes. J Child Fam Stud, 9, 449-460.

Rohr, B.A., Bartlett, E., Duncan, C.R., 2014. Saskatoon Health Region Children and Youth Receiving Mental Health and Addiction Services: Child and Youth Client Profile - April 1, 2013 to March 31, 2014. Saskatoon, Saskatchewan: University of Saskatchewan, Office of Research Chair in Substance Abuse, Department of Sociology.

Rumsey, N., Harcourt, D., 2007. Visible difference amongst children and adolescents: issues and interventions. Developmental Neurorehabilitation, 10(2), 113-123.

Saskatoon Health Region, 2015. Quick Facts: who we are. Retrieved on July 14, 2017, from https://www.saskatoonhealthregion.ca/about/Pages/Quick-Facts.aspx.

Satorra, A., Bentler, E.M., 1994. Corrections to test statistics and standard errors in covariance structure analysis. In A. von Eye \& C.C. Clogg (Eds.), Latent variables analysis: Applications for developmental research (pp. 399-419). Thousand Oaks, CA: Sage.

Sheehan, R., 2017. Mental illness in children: childhood illness and supporting the family. Brain Sci, $7(8), 97$.

StataCorp., 2015. Stata Statistical Software: Release 14. College Station, TX: StataCorp LP. 
Waddell, C., McEwan, K., Shepherd, C.A., Offord, D.R., Hua, J.M., 2005. A Public Health Strategy to Improve the Mental Health of Canadian Children. Can J Psychiatry, 50, 4.

Walrath, C.M., Mandell, D.S., Leaf, P.J., 2001. Responses of children with different intake profiles to mental health treatment. Psychiatr Serv, 52, 196-201.

Weissman, M.M., 1975. The assessment of social functioning: a review of techniques. Arch Gen Psychiatry, 32, 357-365.

Xue, Y., Hodges, K., Wotring, J., 2004. Predictors of outcome for children with behaviour problems served in public health. J Clin Child Adolesc Psychol, 33, 516-523.

Yange, X., Kay, H., Jim, W., 2004. Predictors of Outcome for Children with Behaviour Problems Served in Public Mental Health. J Clin Child Adolesc Psychol, 33(3), 516-523. DOI:

10.1207/s15374424jccp3303_9. 
Table 1

Population characteristics by age group (total number of cases may vary due to missing values)

\begin{tabular}{|c|c|c|c|c|c|c|}
\hline \multirow[b]{2}{*}{ Categorical variables } & \multicolumn{2}{|c|}{$\begin{array}{l}\text { Child }(6-11 \\
\text { years })\end{array}$} & \multicolumn{2}{|c|}{$\begin{array}{c}\text { Adolescent }(12-17 \\
\text { years) }\end{array}$} & \multicolumn{2}{|c|}{ Total } \\
\hline & $\mathrm{n}$ & Percent & $\mathrm{n}$ & Percent & $\mathrm{n}$ & Percent \\
\hline \multicolumn{7}{|l|}{ Gender } \\
\hline Male & 392 & $60.8 \%$ & 296 & $43.4 \%$ & 688 & $51.8 \%$ \\
\hline Female & 253 & $39.2 \%$ & 386 & $56.6 \%$ & 639 & $48.2 \%$ \\
\hline Total & 645 & $100.0 \%$ & 682 & $100.0 \%$ & 1,327 & $100.0 \%$ \\
\hline \multicolumn{7}{|l|}{ Area of residence } \\
\hline Northeast & 67 & $11.6 \%$ & 11 & $10.9 \%$ & 78 & $11.5 \%$ \\
\hline East Centre & 57 & $9.9 \%$ & 15 & $14.9 \%$ & 72 & $10.6 \%$ \\
\hline South & 71 & $12.3 \%$ & 13 & $12.9 \%$ & 84 & $12.4 \%$ \\
\hline Southwest & 108 & $18.7 \%$ & 11 & $10.9 \%$ & 119 & $17.6 \%$ \\
\hline North & 80 & $13.9 \%$ & 12 & $11.9 \%$ & 92 & $13.6 \%$ \\
\hline West & 129 & $22.4 \%$ & 30 & $29.7 \%$ & 159 & $23.5 \%$ \\
\hline Rural \& Prince Albert & 65 & $11.3 \%$ & 9 & $8.9 \%$ & 74 & $10.9 \%$ \\
\hline Total & 577 & $100.0 \%$ & 101 & $100.0 \%$ & 678 & $100.0 \%$ \\
\hline \multicolumn{7}{|l|}{ Number of addresses } \\
\hline 1 & 456 & $79.0 \%$ & 77 & $76.2 \%$ & 533 & $78.6 \%$ \\
\hline 2 & 95 & $16.5 \%$ & 12 & $11.9 \%$ & 107 & $15.8 \%$ \\
\hline $3+$ & 26 & $4.5 \%$ & 12 & $11.9 \%$ & 38 & $5.6 \%$ \\
\hline Total & 577 & $100.0 \%$ & 101 & $100.0 \%$ & 678 & $100.0 \%$ \\
\hline \multicolumn{7}{|l|}{ Living arrangement } \\
\hline Family of origin & 549 & $86.5 \%$ & 99 & $85.3 \%$ & 648 & $86.3 \%$ \\
\hline Foster homes \& other & 39 & $6.2 \%$ & 9 & $7.8 \%$ & 48 & $6.4 \%$ \\
\hline Not provided & 47 & $7.4 \%$ & 8 & $6.9 \%$ & 55 & $7.3 \%$ \\
\hline Total & 635 & $100.0 \%$ & 116 & $100.0 \%$ & 751 & $100.0 \%$ \\
\hline \multicolumn{7}{|l|}{ Primary presenting problem } \\
\hline Aggressive behavior & 59 & $10.4 \%$ & 12 & $11.5 \%$ & 71 & $10.6 \%$ \\
\hline Anxiety & 137 & $24.2 \%$ & 30 & $28.8 \%$ & 167 & $25.0 \%$ \\
\hline Relationship difficulties & 33 & $5.8 \%$ & 4 & $3.8 \%$ & 37 & $5.5 \%$ \\
\hline Cognitive difficulties & 37 & $6.5 \%$ & 4 & $3.8 \%$ & 41 & $6.1 \%$ \\
\hline Behavioral concern & 176 & $31.2 \%$ & 28 & $26.9 \%$ & 204 & $30.5 \%$ \\
\hline Traumatic events & 64 & $11.3 \%$ & 13 & $12.5 \%$ & 77 & $11.5 \%$ \\
\hline Depression & 44 & $7.8 \%$ & 13 & $12.5 \%$ & 57 & $8.5 \%$ \\
\hline Other & 15 & $2.7 \%$ & 0 & $0.0 \%$ & 15 & $2.2 \%$ \\
\hline Total & 565 & $100.0 \%$ & 104 & $100.0 \%$ & 669 & $100.0 \%$ \\
\hline \multicolumn{7}{|l|}{ Number of problems } \\
\hline 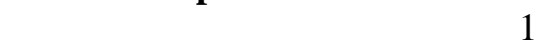 & 195 & $34.5 \%$ & 22 & $21.2 \%$ & 217 & $32.4 \%$ \\
\hline 2 & 164 & $29.0 \%$ & 38 & $36.5 \%$ & 202 & $30.2 \%$ \\
\hline $3+$ & 206 & $36.5 \%$ & 44 & $42.3 \%$ & 250 & $37.4 \%$ \\
\hline Total & 565 & $100.0 \%$ & 104 & $100.0 \%$ & 669 & $100.0 \%$ \\
\hline \multicolumn{7}{|l|}{ Referral source } \\
\hline Professionals & 204 & $32.1 \%$ & 38 & $32.8 \%$ & 242 & $32.2 \%$ \\
\hline Client family/guardian & 290 & $45.7 \%$ & 55 & $47.4 \%$ & 345 & $45.9 \%$ \\
\hline Justice & 12 & $1.9 \%$ & 3 & $2.6 \%$ & 15 & $2.0 \%$ \\
\hline School & 115 & $18.1 \%$ & 16 & $13.8 \%$ & 131 & $17.4 \%$ \\
\hline Other & 14 & $2.2 \%$ & 4 & $3.4 \%$ & 18 & $2.4 \%$ \\
\hline Total & 635 & $100.0 \%$ & 116 & $100.0 \%$ & 751 & $100.0 \%$ \\
\hline
\end{tabular}




\begin{tabular}{|c|c|c|c|c|c|c|}
\hline \multicolumn{7}{|l|}{ Initial CAFAS Total Score } \\
\hline Low $(0-40)$ & 354 & $54.9 \%$ & 237 & $34.8 \%$ & 591 & $44.5 \%$ \\
\hline Medium $(50-90)$ & 235 & $36.4 \%$ & 318 & $46.6 \%$ & 553 & $41.7 \%$ \\
\hline High $(100+)$ & 56 & $8.7 \%$ & 127 & $18.6 \%$ & 183 & $13.8 \%$ \\
\hline Total & 645 & $100.0 \%$ & 682 & $100.0 \%$ & 1,327 & $100.0 \%$ \\
\hline \multicolumn{7}{|l|}{$\begin{array}{l}\text { Pervasive behavioral } \\
\text { impairment (PBI) }\end{array}$} \\
\hline 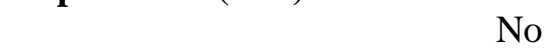 & 569 & $88.2 \%$ & 626 & $91.8 \%$ & 1,195 & $90.1 \%$ \\
\hline Yes & 76 & $11.8 \%$ & 56 & $8.2 \%$ & 132 & $9.9 \%$ \\
\hline $\begin{array}{lll}\text { Total }\end{array}$ & 645 & $100.0 \%$ & 682 & $100.0 \%$ & 1,327 & $100.0 \%$ \\
\hline \multicolumn{7}{|l|}{ Parental capacity development } \\
\hline No & 526 & $82.8 \%$ & 102 & $87.9 \%$ & 628 & $83.6 \%$ \\
\hline Yes & 109 & $17.2 \%$ & 14 & $12.1 \%$ & 123 & $16.4 \%$ \\
\hline Total & 635 & $100.0 \%$ & 116 & $100.0 \%$ & 751 & $100.0 \%$ \\
\hline \multicolumn{7}{|l|}{$\begin{array}{l}\text { Caregiver resources - Family } \\
\text { support }\end{array}$} \\
\hline Minimal (0) & 386 & $62.6 \%$ & 300 & $51.0 \%$ & 686 & $56.9 \%$ \\
\hline Mild (10) & 129 & $20.9 \%$ & 173 & $29.4 \%$ & 302 & $25.1 \%$ \\
\hline Moderate (20) to Severe (30) & 102 & $16.5 \%$ & 115 & $19.6 \%$ & 217 & $18.0 \%$ \\
\hline Total & 617 & $100.0 \%$ & 588 & $100.0 \%$ & 1,205 & $100.0 \%$ \\
\hline \multicolumn{7}{|l|}{$\begin{array}{l}\text { Caregiver resources - Material } \\
\text { needs }\end{array}$} \\
\hline Minimal (0) & 570 & $92.8 \%$ & 547 & $93.0 \%$ & 1,117 & $92.9 \%$ \\
\hline Mild (10) & 34 & $5.5 \%$ & 34 & $5.8 \%$ & 68 & $5.7 \%$ \\
\hline Moderate (20) to Severe (30) & 10 & $1.6 \%$ & 7 & $1.2 \%$ & 17 & $1.4 \%$ \\
\hline Total & 614 & $100.0 \%$ & 588 & $100.0 \%$ & 1,202 & $100.0 \%$ \\
\hline \multicolumn{7}{|l|}{ Number of episodes } \\
\hline (1) & 524 & $81.2 \%$ & 565 & $82.8 \%$ & 1,089 & $82.1 \%$ \\
\hline 2 & 100 & $15.5 \%$ & 108 & $15.8 \%$ & 208 & $15.7 \%$ \\
\hline $3+$ & 21 & $3.3 \%$ & 9 & $1.3 \%$ & 30 & $2.3 \%$ \\
\hline Total & 645 & $100.0 \%$ & 682 & $100.0 \%$ & 1,327 & $100.0 \%$ \\
\hline \multicolumn{7}{|l|}{ Length of stay (month) } \\
\hline 0 & 104 & $16.1 \%$ & 242 & $35.5 \%$ & 346 & $26.1 \%$ \\
\hline $3-6$ & 128 & $19.8 \%$ & 109 & $16.0 \%$ & 237 & $17.9 \%$ \\
\hline $6-9$ & 136 & $21.1 \%$ & 185 & $27.1 \%$ & 321 & $24.2 \%$ \\
\hline $9-12$ & 77 & $11.9 \%$ & 45 & $6.6 \%$ & 122 & $9.2 \%$ \\
\hline $12-15$ & 75 & $11.6 \%$ & 52 & $7.6 \%$ & 127 & $9.6 \%$ \\
\hline $15-18$ & 41 & $6.4 \%$ & 10 & $1.5 \%$ & 51 & $3.8 \%$ \\
\hline $18-21$ & 34 & $5.3 \%$ & 21 & $3.1 \%$ & 55 & $4.1 \%$ \\
\hline $21-24$ & 22 & $3.4 \%$ & 4 & $0.6 \%$ & 26 & $2.0 \%$ \\
\hline $24+$ & 28 & $4.3 \%$ & 14 & $2.1 \%$ & 42 & $3.2 \%$ \\
\hline Total & 645 & $100.0 \%$ & 682 & $100.0 \%$ & 1,327 & $100.0 \%$ \\
\hline
\end{tabular}

SD, Standard Deviation 
Table 2

Median differences, total and subscale scores from entry to exit for children and adolescents $(\mathrm{N}=1,327)$

\begin{tabular}{|c|c|c|c|c|c|c|c|c|}
\hline & \multicolumn{4}{|c|}{ Children (6-11 years, $n=645)$} & \multicolumn{4}{|c|}{ Adolescent (12-17 years, $n=682)$} \\
\hline & $\begin{array}{c}\text { Negative } \\
\text { differences } \\
\text { (better) }\end{array}$ & $\begin{array}{c}\text { Positive } \\
\text { differences } \\
\text { (worse) }\end{array}$ & Ties $^{3}$ & Z score & $\begin{array}{c}\text { Negative } \\
\text { difference }{ }^{1} \\
\text { (better) }\end{array}$ & $\begin{array}{c}\text { Positive } \\
\text { difference }^{2} \\
\text { (worse) }\end{array}$ & Ties $^{3}$ & Z score \\
\hline Total score & 389 & 57 & 199 & $-15.7 * * *$ & 457 & 96 & 129 & $-15.3 * * *$ \\
\hline School subscale & 205 & 40 & 400 & $-10.5 * * *$ & 187 & 63 & 432 & $-7.8 * * *$ \\
\hline Home subscale & 207 & 23 & 415 & $-12.1 * * *$ & 198 & 61 & 423 & $-8.5 * * *$ \\
\hline Community subscale & 24 & 9 & 612 & $-2.4^{*}$ & 72 & 23 & 587 & $-4.9 * * *$ \\
\hline Behavior subscale & 233 & 32 & 380 & $-12.3 * * *$ & 168 & 49 & 465 & $-8.0 * * *$ \\
\hline Mood subscale & 247 & 31 & 367 & $-12.9 * * *$ & 301 & 47 & 334 & $-13.6 * * *$ \\
\hline Self-Harm subscale & 60 & 10 & 575 & $-5.9 * * *$ & 211 & 16 & 455 & $-12.9 * * *$ \\
\hline Substance subscale & 3 & 0 & 642 & $0.250^{\mathrm{a}}$ & 83 & 49 & 550 & $-2.9 * *$ \\
\hline Thinking subscale & 27 & 8 & 610 & $-3.0 * *$ & 59 & 27 & 596 & $-3.3 * *$ \\
\hline
\end{tabular}

${ }^{1}$ Exit score < initial score; ${ }^{2}$ Exit score $>$ initial score; ${ }^{3}$ Exit score = initial score; ${ }^{\text {a Exact }}$ sign test was used

$*$ p-value $<0.05 ; * *$ p-value $<0.01 ; * * *$ p-value $<0.001$ 
Table 3

Comparison of predictors for improvement in level of dysfunction by age group

$$
\text { Child (AMIS }
$$

variables included in

Child (Amis variables

excluded)

\begin{tabular}{|c|c|c|c|c|}
\hline \multicolumn{5}{|l|}{ Logistic regression } \\
\hline Variable & Categories & OR $(95 \% \mathrm{CI})$ & OR $(95 \% \mathrm{CI})$ & OR $(95 \% \mathrm{CI})$ \\
\hline \multirow{3}{*}{ Initial total score } & Low $(0-40)$ & (2) & $x^{2}$ & 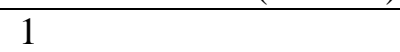 \\
\hline & Medium $(50-90)$ & $4.3(2.7-7.0)^{* * *}$ & $3.7(2.5-5.4)^{* * *}$ & $2.4(1.6-3.5)^{* * *}$ \\
\hline & High $(100+)$ & $9.9(3.1-31.9)^{* * *}$ & $5.8(2.4-14.1)^{* * *}$ & $7.2(3.5-14.9) * * *$ \\
\hline \multirow[t]{2}{*}{ Initial PBI } & Yes & 1 & 1 & 1 \\
\hline & No & $3.8(1.5-9.7)^{* *}$ & $1.6(0.8-3.4)$ & $3.1(1.3-7.4)^{* *}$ \\
\hline \multirow{9}{*}{$\begin{array}{l}\text { Length of stay } \\
\text { (month) }\end{array}$} & $0-3$ & 1 & 1 & 1 \\
\hline & $3-6$ & $2.0(1.0-4.0)$ & $1.5(0.8-2.6)$ & $1.4(0.8-2.4)$ \\
\hline & $6-9$ & $1.8(0.9-3.6)$ & $2.0(1.1-3.6)^{*}$ & $1.9(1.2-2.9)^{* *}$ \\
\hline & $9-12$ & $2.1(0.9-4.6)$ & $2.6(1.3-5.1)^{* *}$ & $1.8(0.9-3.6)$ \\
\hline & $12-15$ & $4.3(1.9-9.5)^{* * *}$ & $4.3(2.2-8.5)^{* * *}$ & $2.6(1.3-5.1)^{* *}$ \\
\hline & $15-18$ & $4.4(1.6-12.1)^{* *}$ & $4.4(1.9-9.9)^{* * *}$ & $6.9(1.2-40.9)^{*}$ \\
\hline & $18-21$ & $4.0(1.4-12.0)^{*}$ & $5.1(2.1-12.8)^{* * *}$ & $5.6(1.5-20.5)^{*}$ \\
\hline & $21-24$ & $1.9(0.6-6.5)$ & $1.6(0.6-4.4)$ & $1.2(0.2-9.3)$ \\
\hline & $24+$ & $4.2(1.4-13.1)^{*}$ & $3.8(1.5-9.9)^{* *}$ & $1.8(0.5-6.1)$ \\
\hline \multirow{3}{*}{$\begin{array}{l}\text { Caregiver } \\
\text { resources - } \\
\text { Family support }\end{array}$} & Minimal (0) & 1 & 1 & 1 \\
\hline & Mild (10) & $0.7(0.4-1.1)$ & $0.5(0.4-0.9)^{* *}$ & $0.9(0.6-1.3)$ \\
\hline & $\begin{array}{l}\text { Moderate (20) to Severe } \\
\text { (30) }\end{array}$ & $1.0(0.6-1.9)$ & $0.6(0.4-1.0)$ & $0.6(0.4-1.0)$ \\
\hline \multirow{3}{*}{$\begin{array}{l}\text { Number of } \\
\text { address }\end{array}$} & 1 & 1 & & \\
\hline & 2 & $1.6(0.9-2.8)$ & & \\
\hline & 3 or more & $1.7(0.6-5.1)$ & & \\
\hline \multirow{7}{*}{$\begin{array}{l}\text { Primary } \\
\text { presenting } \\
\text { problem }\end{array}$} & Behavioural concern & 1 & & \\
\hline & Aggressive behaviour & $2.0(1.0-4.2)$ & & \\
\hline & Anxiety & $2.5(1.4-4.4)^{* *}$ & & \\
\hline & Relationship difficulties & $4.0(1.6-10.0)^{* *}$ & & \\
\hline & Cognitive difficulties & $1.5(0.6-3.6)$ & & \\
\hline & Traumatic events & $1.4(0.6-3.0)$ & & \\
\hline & Depression & $3.1(1.3-7.1)^{* *}$ & & \\
\hline
\end{tabular}

Adolescent (Amis variables excluded) 
Other $\quad 1.7(0.5-6.2)$

\begin{tabular}{llllll} 
Area of & West & 1 & improved & & improved \\
\cline { 3 - 5 } residence & Northeast & $2.4(1.1-4.9)^{*}$ & $33(49.9 \%)$ & $53(41.1 \%)$ & $129(100 \%)$ \\
& East Centre & $1.7(0.8-3.8)$ & $29(50.9 \%)$ & $28(49.1 \%)$ & $57(100 \%)$ \\
& South & $1.9(1.0-3.9)$ & $34(47.9 \%)$ & $37(52.1 \%)$ & $71(100 \%)$ \\
& Southwest & $1.1(0.6-2.1)$ & $74(68.5 \%)$ & $34(31.5 \%)$ & $108(100 \%)$ \\
& North & $2.2(1.1-4.5)^{*}$ & $39(48.8 \%)$ & $41(51.2 \%)$ & $80(100 \%)$ \\
& Rural \& Prince Albert & $3.0(1.4-6.6)^{* *}$ & $26(40.0 \%)$ & $39(60.0 \%)$ & $65(100 \%)$ \\
\hline
\end{tabular}

PBI, Pervasive Behavioural Impairment; OR, odds ratio; CI, Confidence Interval; *p $<0.05 ; * * \mathrm{p}<0.01 ; * * * \mathrm{p}<0.001$ 
Figure 1 Flowchart of subject selection

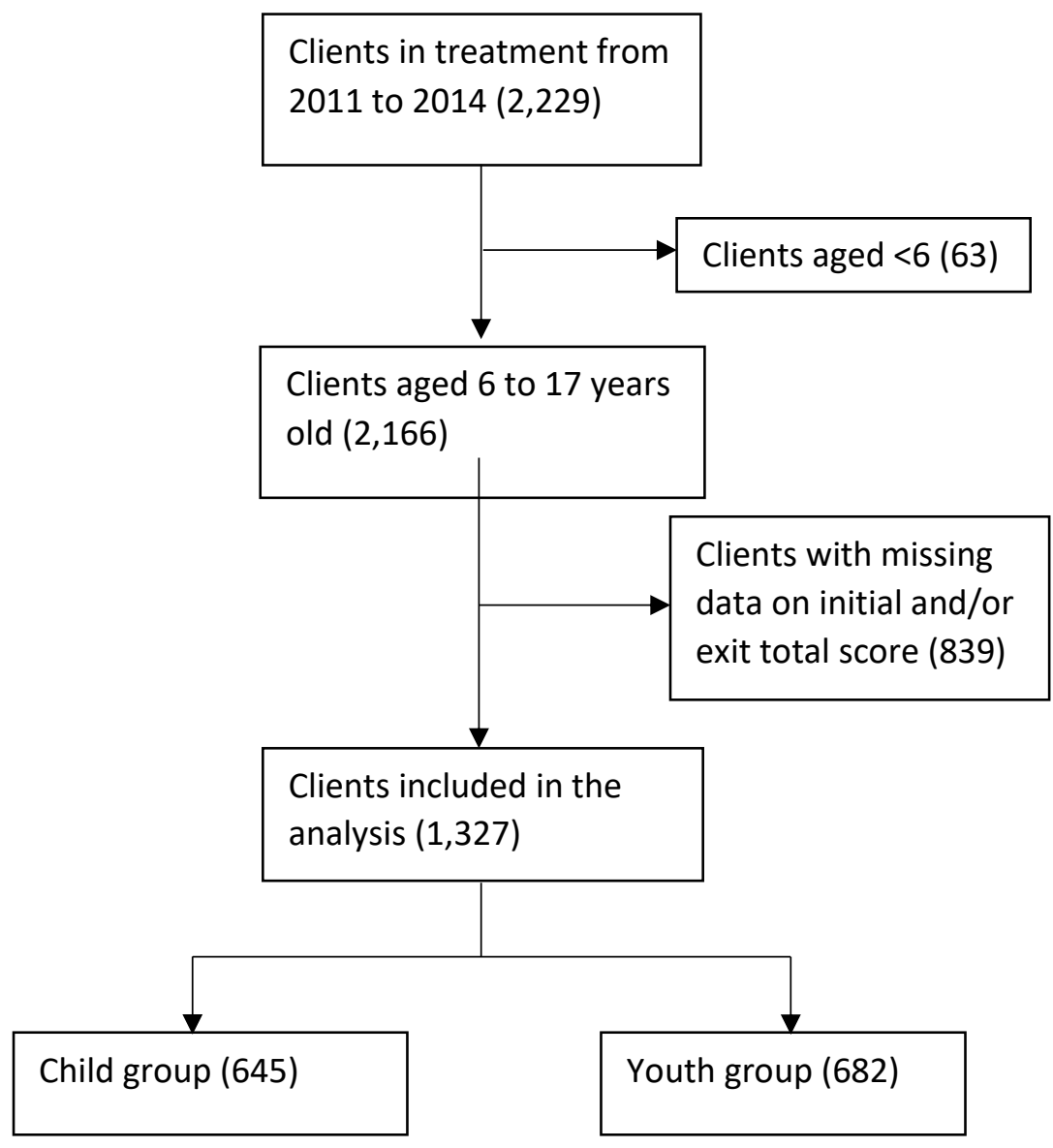


This version is made available under the CC-BY-NC-ND 4.0 license https://creativecommons.org/licenses/by-nc-nd/4.0/ 
This version is made available under the CC-BY-NC-ND 4.0 license https://creativecommons.org/licenses/by-nc-nd/4.0/

Figure 2 Confirmatory factor analysis by age group 


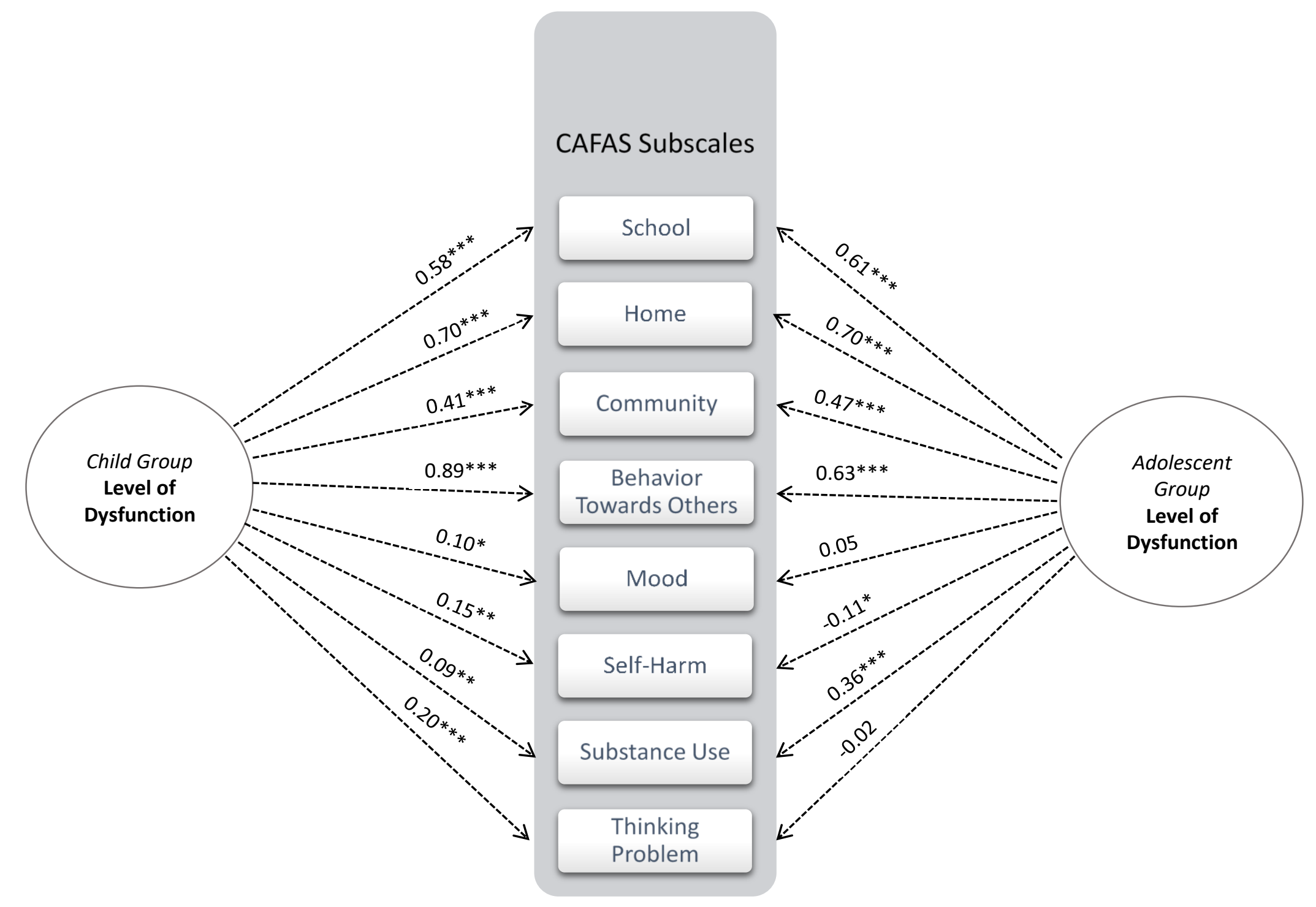

${ }^{*} p<0.05 ;{ }^{* *} p<0.01 ;{ }^{* * *} p<0.001$ 
Figure 3 Area graph of the distribution of initial and exit CAFAS Total Scores for both child and adolescent age groups

\section{CAFAS Total Score differences at Entry and Exit from}

\section{Treatment in Children}

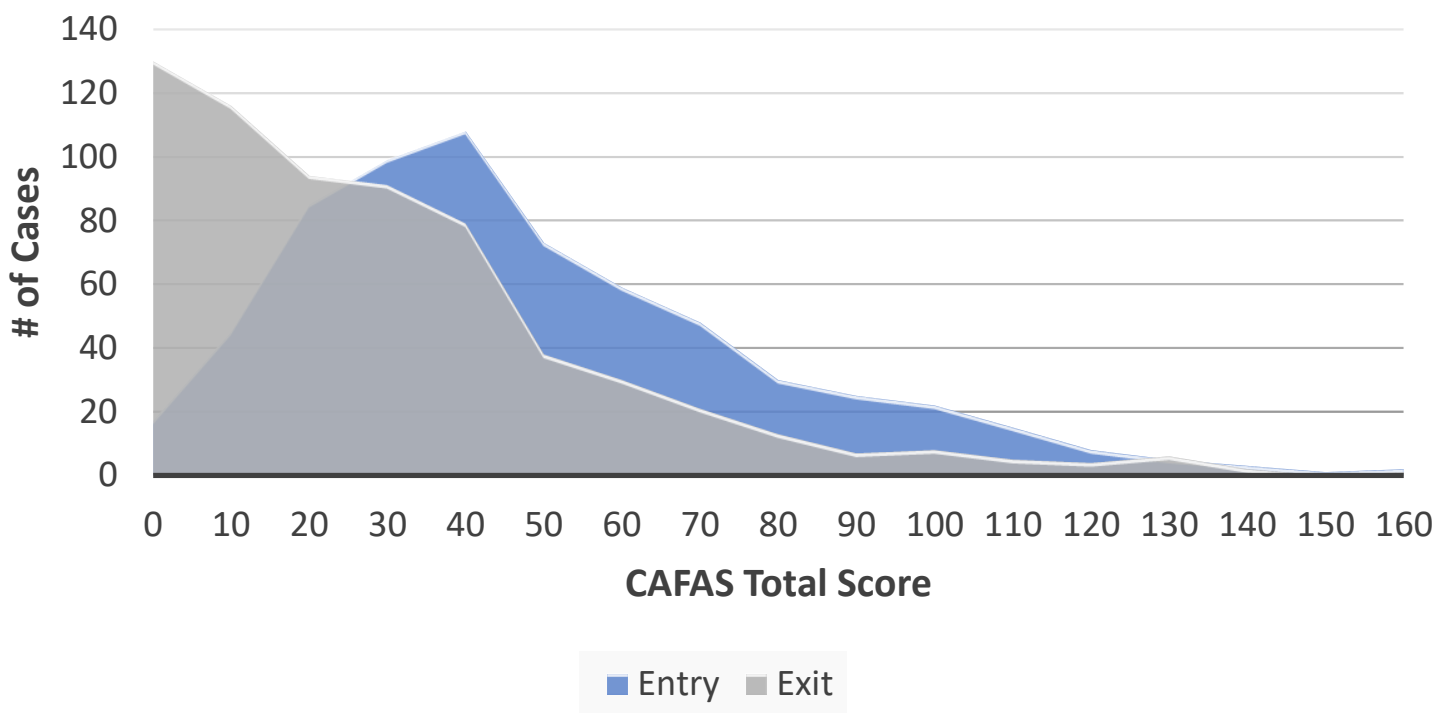

\section{CAFAS Total Score differences at Entry and Exit from Treatment in Adolescents}

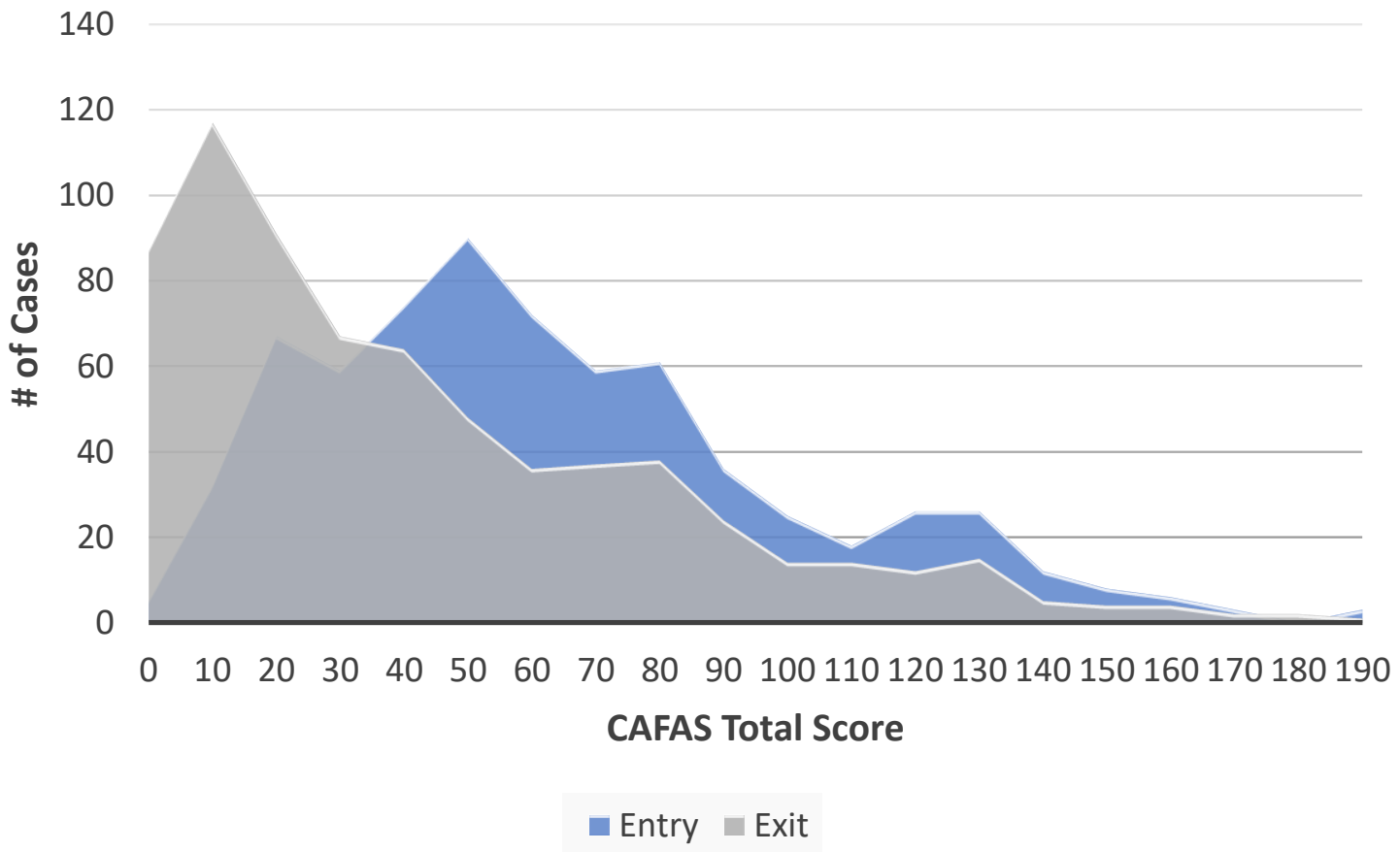


This version is made available under the CC-BY-NC-ND 4.0 license https://creativecommons.org/licenses/by-nc-nd/4.0/ 
Appendix 1 CAFAS assessment rubric ${ }^{1}$

\begin{tabular}{|c|c|c|c|c|}
\hline & \multirow{2}{*}{ Measurement } & \multicolumn{3}{|c|}{ Level of dysfunction } \\
\hline & & Mild $(0-10)$ & Moderate (20) & Severe (30) \\
\hline \multicolumn{5}{|l|}{ Subscales } \\
\hline School & $\begin{array}{l}\text { - Attendance at school } \\
\text { - Behavior in the classroom } \\
\text { - Credits- Academic performance }\end{array}$ & $\begin{array}{l}\text { - Minor problems: } \\
\text { attention, lower } \\
\text { productivity } \\
\text { - Problems that can } \\
\text { be handled by } \\
\text { teacher }\end{array}$ & $\begin{array}{l}\text { - Frequently } \\
\text { truant/suspended } \\
\text { - In or need special setting } \\
\text { - Known by principal } \\
\text { - Failing } 1 / 2 \text { courses }\end{array}$ & $\begin{array}{l}\text { - Out of school } \\
\text { - Serious threat } \\
\text { - Failing most courses } \\
\text { - Special setting not working }\end{array}$ \\
\hline Home & $\begin{array}{l}\text { - Carrying out expectations in the } \\
\text { home - chores, rules, } \\
\text { responsibilities, self-care } \\
\text { - Behavior towards family members } \\
\text { - Run away behavior }\end{array}$ & $\begin{array}{l}\text { - Frustrating to } \\
\text { caregiver } \\
\text { - Balking chores } \\
\text { - Repeatedly told to } \\
\text { do chores }\end{array}$ & $\begin{array}{l}\text { - Persistent non- } \\
\text { compliance with rules } \\
\text { - Runaway overnight; } \\
\text { where known } \\
\text { - Moderate damage } \\
\text { - Profanity (not okay) }\end{array}$ & $\begin{array}{l}\text { - Not in home } \\
\text { - Serious threats } \\
\text { - Intimidation } \\
\text { - Major damage } \\
\text { - Runaway over night; where } \\
\text { not known } \\
\text { - Must be monitored } \\
\text { - Interferes with caregiver } \\
\text { doing day to day }\end{array}$ \\
\hline Community & $\begin{array}{l}\text { How the child behaves in the } \\
\text { community: } \\
\text { - Violation of persons or property } \\
\text { - Fire setting in home included } \\
\text { - Do not endorse if: youth was the } \\
\text { victim; act was accidental; youth } \\
\text { was acting in self-defense } \\
\text { - Do endorse if: youth gets into legal } \\
\text { trouble; reliable information } \\
\text { ("good faith") from others about } \\
\text { youth's delinquent behaviour }\end{array}$ & $\begin{array}{l}\text { - Minor, single } \\
\text { offences: vandalism, } \\
\text { shoplifting, playing } \\
\text { with fire }\end{array}$ & $\begin{array}{l}\text { - In system, or at risk for } \\
\text { moderately serious } \\
\text { offence: not confronting } \\
\text { victim, stealing, sexually } \\
\text { inappropriate - adults } \\
\text { concerned, repeatedly } \\
\text { playing with fire \& } \\
\text { damage could occur } \\
\text { - Probation }\end{array}$ & $\begin{array}{l}\text { - In system or should be in } \\
\text { system for serious offence: } \\
\text { confronting victim, robbery, } \\
\text { selling drugs, prostitution, } \\
\text { deliberate damage, sexual } \\
\text { assault, deliberate fire } \\
\text { starting with malicious } \\
\text { intent }\end{array}$ \\
\hline $\begin{array}{l}\text { Behaviour } \\
\text { Toward } \\
\text { Others }\end{array}$ & $\begin{array}{l}\text { How the child relates to others: } \\
\text { - Patterns of behavior towards } \\
\text { others }\end{array}$ & $\begin{array}{l}\text { - Poor judgement } \\
\text { - Easily annoyed } \\
\text { - Annoying to others }\end{array}$ & $\begin{array}{l}\text { - Fighting } \\
\text { - Promiscuity }\end{array}$ & $\begin{array}{l}\text { - Behavior consistently odd } \\
\text { - Behavior could cause } \\
\text { serious harm }\end{array}$ \\
\hline
\end{tabular}




\begin{tabular}{|c|c|c|c|c|}
\hline & $\begin{array}{l}\text { - Displays of anger } \\
\text { - Poor judgment } \\
\text { - Inappropriate sexual behavior } \\
\text { - Cruelty to animals }\end{array}$ & - Poor peer relations & $\begin{array}{l}\text { - Inappropriate sexual } \\
\text { behavior } \\
\text { - Spiteful/vindictive } \\
\text { - Risky behaviours could } \\
\text { cause injury } \\
\text { - Bullying } \\
\text { - Gang activity } \\
\text { - Frequent anger outburst }\end{array}$ & $\begin{array}{l}\text { - Abuse/sexual abuse to } \\
\text { others } \\
\text { - Constant intimidation } \\
\text { - Deliberately \& severely cruel } \\
\text { to animals }\end{array}$ \\
\hline $\begin{array}{l}\text { Moods \& } \\
\text { Emotions }\end{array}$ & $\begin{array}{l}\text { - Anxiety } \\
\text { - Fear } \\
\text { - Worry } \\
\text { - Depression } \\
\text { - Separation anxiety } \\
\text { - Does NOT include anger/hostility } \\
\text { (scored on Behaviour Towards } \\
\text { Others) }\end{array}$ & $\begin{array}{l}\text { - Self-critical } \\
\text { - Easily distressed } \\
\text { when make } \\
\text { mistakes } \\
\text { - Sad or anxious if } \\
\text { criticized } \\
\text { - Notable emotional } \\
\text { restriction }\end{array}$ & $\begin{array}{l}\text { - Depression or anxiety at } \\
\text { least } 1 / 2 \text { the time, with } \\
\text { one disturbance (e.g., } \\
\text { sleep, eating, energy) } \\
\text { - Emotional blunting from } \\
\text { trauma } \\
\text { - Separation anxiety }\end{array}$ & $\begin{array}{l}\text { - Viewed as odd/strange } \\
\text { - Depression of anxiety with } \\
\text { school incapacitation, social } \\
\text { isolation or suicidal intent }\end{array}$ \\
\hline Self-harm & $\begin{array}{l}\text { Score all self-destructive behavior: } \\
\text { - Suicidal behavior } \\
\text { - Behavior not life-threatening but } \\
\text { not trivial } \\
\text { - Behavior trivial and unlikely to } \\
\text { cause serious injury }\end{array}$ & $\begin{array}{l}\text { - Non-accidental self- } \\
\text { harm that is unlikely } \\
\text { to cause harm (e.g., } \\
\text { scratching skin, } \\
\text { picking skin) }\end{array}$ & $\begin{array}{l}\text { - Talking about killing self } \\
\text { - Cutting or other non- } \\
\text { accidental self-harm or } \\
\text { mutilation }\end{array}$ & $\begin{array}{l}\text { - Intent to die/clear plan } \\
\text { - Self-destructive behavior } \\
\text { which could result in death } \\
\text { (e.g., eating disorder, } \\
\text { running in front of car) }\end{array}$ \\
\hline Substance Use & $\begin{array}{l}\text { - Alcohol } \\
\text { - Street drugs } \\
\text { - Inhalants } \\
\text { - Misuse of prescription drugs } \\
\text { - Misuse of over-the counter drugs } \\
\text { - Tobacco use is not scored } \\
\text { - Do not rate religious or cultural use } \\
\text { - } 12 \text { or younger use lower band of } \\
\text { items } \\
\text { - Score all "hard" drugs at severe } \\
\text { level }\end{array}$ & $\begin{array}{l}\text { - Regular usage } \\
\text { - High or intoxicated } \\
\text { at least once/week }\end{array}$ & $\begin{array}{l}\text { - Use interferes with } \\
\text { functioning } \\
\text { - Use gets person into } \\
\text { trouble (e.g., arguments, } \\
\text { breaks rules) } \\
\text { - Use endangers (e.g., } \\
\text { rape) }\end{array}$ & $\begin{array}{l}\text { - Lifestyle centers around } \\
\text { - Withdrawal symptoms } \\
\text { - Expelled or fired } \\
\text { - Intoxicated or high more } \\
\text { than } 2 x / \text { week } \\
\text { - Pregnant while using } \\
\text { - Blackouts } \\
\text { - Drinks alone }\end{array}$ \\
\hline
\end{tabular}




\begin{tabular}{|c|c|c|c|c|}
\hline Thinking & $\begin{array}{l}\text { - Items refers to behaviours that } \\
\text { may warrant a referral to a } \\
\text { psychiatrist } \\
\text { - Dysfunctional thought processes or } \\
\text { communications } \\
\text { - Pathological thought processes } \\
\text { - Obsessions, fantasies, } \\
\text { hallucinations } \\
\text { - Disorders including autism, PDD, } \\
\text { schizophrenia can be scored here }\end{array}$ & $\begin{array}{l}\text { - Occasional difficulty } \\
\text { in communications, } \\
\text { in behavior, or in } \\
\text { interactions with } \\
\text { others } \\
\text { - Eccentric/odd } \\
\text { speech; odd beliefs } \\
\text { - If older than } 8 \text { years } \\
\text { - magical thinking } \\
\text { - Unusual perceptual } \\
\text { experiences }\end{array}$ & $\begin{array}{l}\text { - Frequent difficulty in } \\
\text { communication/behavior } \\
\text { OR specialized setting } \\
\text { needed due to any of the } \\
\text { following: } \\
\text { - Disorganized } \\
\text { communications } \\
\text { - Frequent } \\
\text { obsessions/suspicion } \\
\text { - Intermittent } \\
\text { hallucinations } \\
\text { - Frequent marked } \\
\text { confusion, or evidence of } \\
\text { short-term memory loss } \\
\text { - Pre-occupying fantasies } \\
\text { or cognitions }\end{array}$ & $\begin{array}{l}\text { - Cannot attend a normal } \\
\text { school classroom, does not } \\
\text { have normal friendships, } \\
\text { and cannot interact } \\
\text { adequately in the } \\
\text { community due to: } \\
\text { - Incoherent communication; } \\
\text { loosening of associations } \\
\text { - Flight of ideas } \\
\text { - Echolalia } \\
\text { - Idiosyncratic language } \\
\text { - Frequent } \\
\text { hallucinations/delusions } \\
\text { - Pattern of short-term } \\
\text { memory loss } \\
\text { - Disorientation to time/place }\end{array}$ \\
\hline \multicolumn{5}{|c|}{ Caregiver Scales } \\
\hline $\begin{array}{l}\text { Material } \\
\text { Needs }\end{array}$ & $\begin{array}{l}\text { - Basic material needs: } \\
\text { - Food } \\
\text { - Housing (safety, privacy) } \\
\text { - Medical attention } \\
\text { - Reasonably safe neighbourhood }\end{array}$ & $\begin{array}{l}\text { - Occasional negative } \\
\text { impact on youth due } \\
\text { to disruption in } \\
\text { youth needs for } \\
\text { food, shelter, } \\
\text { medical, or } \\
\text { neighbourhood } \\
\text { safety }\end{array}$ & $\begin{array}{l}\text { - Frequent negative } \\
\text { impact or major } \\
\text { disruption in youth } \\
\text { needs for food, shelter, } \\
\text { medical, or } \\
\text { neighborhood safety }\end{array}$ & $\begin{array}{l}\text { - Needs for food, shelter, } \\
\text { medical or neighbourhood } \\
\text { safety are not met \& severe } \\
\text { risk to health }\end{array}$ \\
\hline $\begin{array}{l}\text { Family/Social } \\
\text { Support }\end{array}$ & $\begin{array}{l}\text { - Caregiver behavior is rated } \\
\text { - Relative to child's needs } \\
\text { - Parental judgment } \\
\text { - Supervision problems } \\
\text { - Conflict problems } \\
\text { - All forms of abuse }\end{array}$ & $\begin{array}{l}\text { - Unable to provide } \\
\text { warmth } \\
\text { - Frequent arguments } \\
\text { - Poor family relations } \\
\text { \& problem solving } \\
\text { - Inconsistent } \\
\text { parenting } \\
\text { - Inadequate } \\
\text { supervision/firmness }\end{array}$ & $\begin{array}{l}\text { - Youth developmental } \\
\text { needs exceed resources } \\
\text { - Marked impairment of } \\
\text { judgement } \\
\text { - Family conflict } \\
\text { - Not supportive of } \\
\text { traumatized youth } \\
\text { - Domestic violence } \\
\text { - Threat of violence }\end{array}$ & $\begin{array}{l}\text { - Severe lack of resources, } \\
\text { youth needs not met } \\
\text { - Gross impairment of } \\
\text { judgement (e.g., substance, } \\
\text { mental) } \\
\text { - Rejecting, does not want } \\
\text { youth home } \\
\text { - Risk of abuse }\end{array}$ \\
\hline
\end{tabular}


- Youth kicked out with no provisions

- Not protecting youth who was severely traumatized

- Severe domestic abuse

- Openly unlawful or approves of youth being unlawful

${ }^{1}$ Source: adapted from https://www.aero-aoce.org/uploads/6/6/0/0/6600183/cafas_ppt_melaniebarwick.pdf 